\title{
A Pavlovian analysis of food-attraction conditioning in the snail Helix aspersa
}

\author{
M. A. UNGLESS \\ University of York, York, England
}

\begin{abstract}
Following brief pairing of an odor with a feeding experience (food-attraction conditioning), snails will lower their tentacles when subsequently presented with that odor alone. Three experiments investigated the possible behavioral mechanism mediating food-attraction conditioning in the snail Helix aspersa. It is suggested that food-attraction conditioning is an example of Pavlovian conditioning. In this case, the odor (conditioned stimulus) is paired with oral stimulation (unconditioned stimulus), which elicits lowering of the tentacles (unconditioned response). Following conditioning, the odor comes to elicit lowering of the tentacles (conditioned response). Experiment 1 ruled out nonassociative effects, such as habituation and sensitization, using an unpaired control group. Experiment 2 provided further evidence against a role for habituation of neophobia, through the demonstration of extinction following conditioning. In Experiment 3, an omission procedure was used to rule out the possible role of instrumental contingencies.
\end{abstract}

Several gastropod molluscs show increased preference for an odor following the pairing of that odor with a feeding experience (e.g., Croll \& Chase, 1980; Desbuquois \& Daguzan, 1995; Sahley, Martin, \& Gelperin, 1990). In more detailed examinations of this behavioral change, in Helix pomatia (Teyke, 1995a) and Achatina fulica (Chase $\&$ Croll, 1981), it has been found that the pairing results in an ability to locate the odor source, an ability not seen in naive snails. This phenomenon has been called foodattraction conditioning (Teyke, 1995a).

It has also been observed that odor-feeding pairings alter tentacle movements. If a naive snail is presented with the odor of a novel food, its posterior tentacles will remain upright. If the snail is then allowed to feed on that food, it will subsequently lower its tentacles in the presence of the odor (Peschel, Straub, \& Teyke, 1996). The behavioral change survives dissection and can be analyzed in the isolated nervous system (Peschel et al., 1996). It has also been reported that nitric oxide synthesis is necessary for acquisition, whereas serotonin is not (Teyke, 1996). Given the success with which the neuronal basis of learning has been investigated in other gastropods (for reviews, see Carew \& Sahley, 1986; Krasne \& Glanzman, 1995; Mpitsos \& Lukowiak, 1985), there is good reason to be optimistic regarding the elucidation of the cellular mechanisms mediating food-attraction conditioning in Helix.

This research was supported by a grant from the Biotechnology and Biological Sciences Research Council. I would like to thank Euan Macphail for invaluable discussions concerning the conduct of this research and throughout the preparation of this article, and Geoff Hall, Charlotte Bonardi, and R. Chase for many helpful comments on an earlier draft. Correspondence concerning this article should be addressed to M. A. Ungless, Department of Psychology, University of York, Heslington, York, YO1 5DD, England (e-mail:mau100@york.ac.uk).

-Accepted by previous editor, Robert A. Rescorla
However, if a neurophysiological investigation is to be successful, it must be clear what the animal is learning at a behavioral level. In this paper, it is proposed that one of four behavioral mechanisms could be mediating foodattraction conditioning: Two are nonassociative mechanisms (sensitization and habituation), and two are associative (classical conditioning and instrumental conditioning). Before I discuss these mechanisms, a more detailed description of the feeding episode will be necessary. Feeding involves a complex of stimuli and responses. First, the snail experiences an odor that can be thought of as a tobe-conditioned stimulus (CS). As the snail begins feeding, it receives the second stimulus-oral stimulation. Since it has been shown that other stimuli involved in feeding, such as lip and ingestive stimulation, do not promote learning (Teyke, 1995b), oral stimulation is the unconditioned stimulus (UCS), and it elicits tentacular lowering, the unconditioned response (UCR). Typically, the UCR is elicited after a short delay $(\approx 10 \mathrm{sec})$. Following feeding, the odor alone comes to elicit the same response, now a conditioned response (CR).

One of four mechanisms could conceivably result in the CS coming to elicit the CR. First, sensitization: Feeding could cause a general increase in arousal, which could in turn lead to increased responding to all stimuli. If this were the case, snails would exhibit increased responding to all odors, not just the one paired with oral stimulation. It has already been shown that, in fact, responding is stimulus specific in Helix pomatia, which suggests that the general arousal account is incorrect (Teyke, 1995a). Second, habituation of neophobia: For instance, if snails exhibit neophobia, this would inhibit responding. With repeated exposure to the odor the neophobia would habituate, resulting in an increase in responding. Although some findings suggest that this is an inadequate account of foodattraction conditioning, in Helix pomatia (Teyke, 1995a), 
they are not conclusive, for reasons which will be discussed in more detail in the introduction to Experiment 2. Third, classical conditioning: The CS elicits the CR as a result of the snail's detecting a relationship between the CS and the UCS. Consequently, the snail forms an association between the CS and the UCS (or the response); conditioned responding is subsequently elicited by the $\mathrm{CS}$ alone. Fourth, instrumental conditioning: The snail could be detecting the relationship between the response (lowering the tentacles) and the continuation of the UCS. Of course, at the beginning of the feeding episode, it is the UCS that elicits tentacle lowering. Once the response has occurred, however, it reliably signals the continued presentation of the UCS (a reinforcing event); the snail might detect this instrumental relationship. That is, the snail could be learning to make the response, in the presence of the odor, in order to obtain continued presentation of the food.

The following experiments were performed in an attempt to resolve which of these mechanisms mediates food-attraction conditioning.

\section{EXPERIMENT 1}

There is convergent evidence that food-attraction conditioning consists neither of sensitization nor of habituation. It is stimulus specific, and odor exposure alone does not result in learning (Croll \& Chase, 1980; Teyke, 1995a). However, conventionally, to demonstrate that an effect is associative, a comparison is made with an unpaired control group (for the similar case with Limax, see Sahley et al., 1990). The unpaired control group receives both stimuli, but they are separated in time. Consequently, both groups receive the same amount of exposure to each stimulus, but not the same temporal relationship.

In Experiment 1, snails were fed on one food and they also received an odor from a second food, either paired or unpaired with the feeding experience. Following this, responding to the second odor was tested.

\section{Method}

Subjects. Thirteen experımentally naive snaıls were used. Prıor to the experiment, the snails were maintained on rat food and housed in large groups. They were food deprived for 10 days prior to, and throughout, the experiment. The snalls were housed throughout the experiment in a cool $\left(\approx 20^{\circ} \mathrm{C}\right)$ dark room, in individual plastic containers $(110 \times 80 \times 48 \mathrm{~mm})$ with air holes in the top half of the sidewalls. Each pot contained a small amount of water. The experiment was conducted at approximately $20^{\circ} \mathrm{C}$, with a dim red light on.

Apparatus. A plastic perforated surface $(500 \times 500 \mathrm{~mm} ; 2.5-$ mm-diameter holes) was used. It was supported at each corner above the table $(60 \mathrm{~mm}$ for testing, to allow a pot to be placed beneath it, and $30 \mathrm{~mm}$ for conditioning, to allow a slice of apple to be placed beneath it). For the odor-alone procedure, plastic contaners $(110 \times 80 \times 48 \mathrm{~mm})$ with perforated bases were used. The test odor stımulus was provided by a plastıc pot $(110 \times 80 \times 48 \mathrm{~mm})$ containing food slices.

Procedure. Group Paired $(n=6)$ fed on carrot for 10 min. A slice of apple, placed under the perforated surface, provided the second odor. Therefore, apple odor was the CS and feeding on carrot provided the UCS. Prior to conditioning, the snalls were dipped in water and placed on their sides to induce activity. After each snail had emerged from its shell, it was placed onto the perforated surface. A small piece of food $\left(\approx 1 \mathrm{~cm}^{3}\right)$ was then placed immediately in front of the snail, which was allowed to feed for $10 \mathrm{~min}$ (the 10 min began $5 \mathrm{sec}$ after presentation of the food, by which time the snail had typically begun eating). The snal was then returned to its container.

Group Unpaired ( $n=7$ ) received $10 \mathrm{~min}$ of exposure to apple odor alone (the CS), provided by a shice of apple placed beneath the perforated surface of a pot. The mean time of day of odor exposure was the same for both groups. One hour after apple odor exposure (the CS), Group Unpaired fed on carrot (the UCS) for $10 \mathrm{~min}$.

On the following day, all snails were tested with apple odor. They were tested one at a time. Each snail was first placed on the perforated surface (supported above the table). Testıng began after the snail had begun moving forward. Responding was recorded for 2 min during stimulus presentation. If the snall reached the edge of the arena in this time, it was placed in the middle of the arena and the trial resumed $30 \mathrm{sec}$ later. This occurred very rarely and did not disrupt responding. The odor stımulus was provided by a container $(110 \times 80 \times 48 \mathrm{~mm})$, full of slices of apple. The container was placed directly underneath the snail The snall's left posterior tentacle was observed, from the side of the snail, every $10 \mathrm{sec}$ for $2 \mathrm{~min}$ (to simplify the testing procedure, only one tentacle was observed). For each of the 12 observations, a CR was scored if the tentacle was lowered to, or below, the horizontal. Therefore, each snall received a response score that could range from 0 to 12 . After testing, the snail was returned to its container. The snails were tested in a random order; the experimenter was unaware of each snall's experimental history.

This training and testıng regime was repeated for the same snails, over the following 2 days, since a significant group difference did not emerge after the first test.

\section{Results and Discussion}

Figure 1 shows the mean responses made by Groups Paired and Unpaired. It is clear that Group Paired exhibited more responding on both test days. An analysis of variance (ANOVA) revealed a significant effect of group $[F(1,11)$ $=7.8, p<.05]$. Neither the interaction $[F(1,11)<1]$ nor the effect of test $[F(1,11)<1]$ was significant.

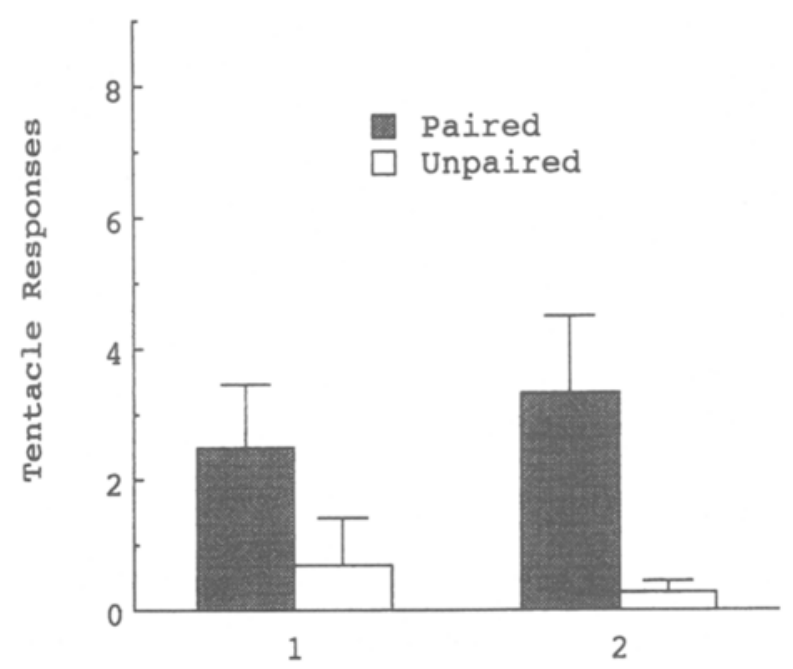

Figure 1. Experiment 1: Mean (+ standard error) number of tentacle lowering responses made by Groups Paired and Unpaired after the first and second training trials. 
As would be expected by an associative account of food-attraction conditioning, exposure to the stimuli unpaired did not promote learning. The use of a traditional control group, then, provided evidence to support an associative interpretation of food-attraction conditioning. However, as discussed in the introduction to Experiment 2 , that evidence was perhaps not conclusive.

\section{EXPERIMENT 2}

Experiment 1 demonstrated that pairing of the stimuli was necessary for learning to occur. However, it seems reasonable to question whether odor exposure alone should be equated with the odor experienced during conditioning. It is a general problem, faced by all cases of simultaneous conditioning, that the CS may be processed differently when presented with the UCS than when presented alone. The problem is perhaps more obvious for foodattraction conditioning. For instance, the snail is closer to the odor source during feeding. Indeed, during feeding the snail lowers its tentacles, bringing them even closer to the odor source. It may be that during feeding the snail is more receptive to, or pays more attention to, odors. Consequently, mere odor exposure is not a decisive test of the habituation account. However, a demonstration of extinction of conditioned responding after conditioning would be unequivocal: The habituation account predicts that odor exposure after conditioning should increase, or at least maintain, responding; if exposures of the odor after conditioning attenuate responding, the habituation account may be rejected.

In Experiment 2, two groups fed on a novel food and were tested for responding to the odor alone. Following this, one group received CS-alone presentations, and both groups were then retested.

\section{Method}

Subjects. Twelve nave snals were used. They were food deprived for 4 days before the experiment began. All other detalis were the same as for Experiment 1.

Apparatus. The same apparatus was used as for Experiment 1.

Procedure. In Stage I, both groups recelved one session of feeding with carrot for $10 \mathrm{~min}$. In this experiment, the odor of the UCS (carrot) acted as the CS. This procedure was essentially the same as that used for Experıment 1 , and it produced sımilar results. It did not, of course, allow the CS and UCS to be unpaired, as was required for Experiment 1, but that was not required for this experiment. All snails were tested the following day, with carrot odor, in the same manner as in Experiment 1. Five hours after the Stage 1 test ended, Group N-ext $(n=6)$ received two 10-min exposures to the plastic containers, with no odor present. There was a $10-\mathrm{m} 1 n$ intertrial interval (ITI), which the snails spent in their home containers. Thirty minutes after this ended, Group $\operatorname{Ext}(n=6)$ recelved two 10 -min exposures of the CS (carrot odor) in the plastic contaners $(I T I=10 \mathrm{~min})$. The odor was provided by three slices of carrot placed directly underneath the perforated base of the container. Group N-ext was dealt with first, to avold any exposure to the odor that might have lingered following the exposure recelved by Group Ext. The following day all snails were tested with carrot odor, in the same manner as for Experiment 1 Durıng each test session, the snails were tested in a random order; the expermenter was unaware of each snall's experimental history.

\section{Results and Discussion}

Figure 2 shows mean tentacle response made during odor presentation for both groups at both stages. The figure shows that both groups exhibited substantial levels of responding after the initial conditioning in Stage 1. It is also clear that the extra presentations of the CS, to Group Ext, attenuated responding when tested in Stage 2. An ANOVA revealed a significant interaction of group $X$ stage $[F(1,10)=8.6, p<.05]$. Analyses of the simple main effects revealed a significant group difference in Stage 2 $[F(1,10)=4.9, p<.05]$; furthermore, the decrease in responding seen in Group Ext was significant $[F(1,10)=$ $5.4, p<.05]$; the increase in responding seen in Group $\mathrm{N}$-ext was not significant $[F(1,10)=3.34, p>.05]$.

This experiment demonstrated that food-attraction conditioning is not the result of habituation of neophobia. If that had been the case, the CS-alone presentations should have enhanced responding; in fact, CS-alone presentations attenuated responding. The results from Experiments 1 and 2 strongly suggest that food-attraction conditioning is not mediated by a nonassociative mechanism. Experiment 3 was an attempt to decide between the two remaining mechanisms: classical conditioning and instrumental conditioning.

\section{EXPERIMENT 3}

Explicitly, at least, food-attraction conditioning is a classical Pavlovian procedure: The CS is paired with the UCS, the animal's behavior having no effect on this relationship. Implicit in most Pavlovian procedures, however, are instrumental contingencies (see Mackintosh, 1983). It is clear that, in the present instance, although it was the UCS that initially elicited the response, the re-

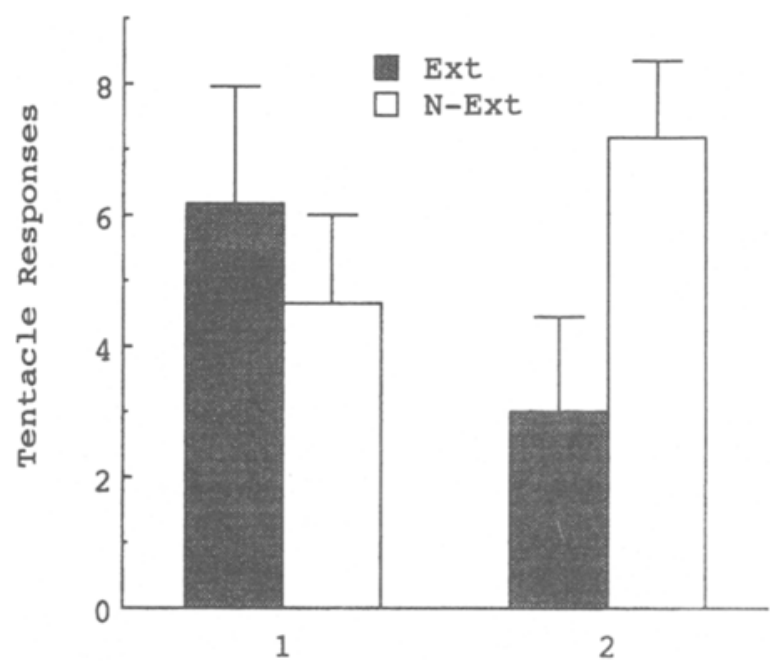

Figure 2. Experiment 2: Mean (+ standard error) number of tentacle lowering responses made by both groups after conditioning (Stage 1), and then after extinction (Stage 2). During Stage 1 , both groups received conditioning. During Stage 2, Group Ext received CS exposure; Group N-ext experienced only the context. 
sponse signaled continued presentation of the UCS (as discussed previously). It could have been, therefore, that the snail was detecting the instrumental relationship between making the response and continued presentation of the UCS. Resolution of this problem could be achieved by using an omission procedure (Sheffield, 1965). During omission training, every time the animal makes a response in the presence of the CS, the UCS is omitted. Thus, the response now causes UCS omission, rather than continuation, and the CS-UCS relationship, although disrupted, still exists (on trials without a response). If a $\mathrm{CR}$ is still acquired under such a procedure, it is clear that it cannot be attributed to the instrumental relationship between the response and the continuation of the UCS: By elimination, acquisition of the CR can be attributed to the relationship between the CS and the UCS.

Food-attraction conditioning lends itself well to an omission procedure for the following reasons. When the snail begins to feed, it typically makes the UCR after some $10 \mathrm{sec}$ (and often considerably longer). It is therefore possible for the snail to receive CS-UCS pairings in the absence of the response (for the period before the UCR is elicited). In Experiment 3, if the response was made, the food was removed (i.e., both the CS and the UCS were removed). This means that, although conditioning might be disrupted through the removal of the food, the snails did not receive any CS-alone presentations. It was therefore possible to give an omission-trained snail the same amount of CS and UCS exposure, and the same relationship (they were always paired), as that given to a snail conditioned under the procedure of Experiment 1. However, in the omission procedure, the response was never paired with the continuation of the UCS. Indeed, the response caused removal of the UCS. If the snail still acquired a CR, it would be the result of the CS-UCS relationship, and not of any rewarding instrumental relationship.

It is, however, not possible on the basis of successful acquisition under an omission schedule, to rule out the further possibility that an omission-trained snail might have learned the punishing instrumental relationship (i.e., that the response signaled UCS omission). Traditionally, a yoked control group was required (Mackintosh, 1983): For every omission-trained snail, a yoked control snail received exactly the same pattern of CS-UCS presentations, regardless of its behavior. If, following this training, the yoked controls showed responding at the same level as the omission group, the possibility that the snails could detect the punishing instrumental relationship could also be discarded. Furthermore, a yoked group would control for factors such as length of training session and number of stimulus onsets.

\section{Method}

Subjects. A total of 101 naive snals were used. Five replications were run $(n$ (nave) $=9,5,8,6,8 ; n$ (omission) $=5,4,2,3,2$, $n$ (yoked) $=5,4,2,3,2 ; n$ (cond) $=5,6,8,6,8)$. They were food deprived for 14 days prior to conditionıng. Other details were the same as for Experiment 1.

Apparatus. All details were the same as for Experiment 1.
Procedure. As in Experıment 2, the odor of the UCS (apple in this case) served as the CS. Group Omission snalls were presented with a small piece of apple, on which they fed. The omission schedule was implemented as follows: As soon as etther of the posterior tentacles was lowered to, or below, the horizontal, the apple was removed. As discussed previously, this typically occurred after $10 \mathrm{sec}$ (although sometımes considerably longer). The apple was replaced in front of the snail, allowing resumption of feeding, when both tentacles returned to a position clearly above the horizontal. It normally took several seconds for the tentacles to return to the upright position, although it often took longer. The duration of each feeding episode, before the tentacles were lowered, was recorded. This regime continued until the snail received a cumulative total of $5 \mathrm{~min}$ of feeding, in the absence of the response. Conditioning was restricted to $5 \mathrm{~min}$, because the omission procedure often took up to $20 \mathrm{~min}$ per snail. Following each omission-trained snail, a snail from Group Yoked received the same pattern of stimulus presentatıons. During the omission procedure, the experimenter provided a verbal commentary on the details of the stimulus presentations. An audio recording was made, and it was played back for the Yoked procedure. Group Cond recelved $5 \mathrm{~min}$ of conditıoning with apple, according to the procedure used in Experiment 2. Group Naive received no trainıng. On the following day, all snails were tested with apple odor, as in Experiment 1. The snalls were tested in a random order; the experimenter was unaware of each snall's experimental history.

\section{Results and Discussion}

Figure 3 shows that responding to the CS in Group Naive was low. Of most interest, Groups Omission, Yoked, and Cond exhibited substantial levels of responding, and there was little difference between these three groups. It was originally planned to run two replications. However, although the pattern of results was, at that stage, the same as that seen in Figure 3, Group Cond did not differ significantly from any of the other groups. Consequently, three more replications were run, in an attempt to obtain a clearer account of Group Cond's performance. The data

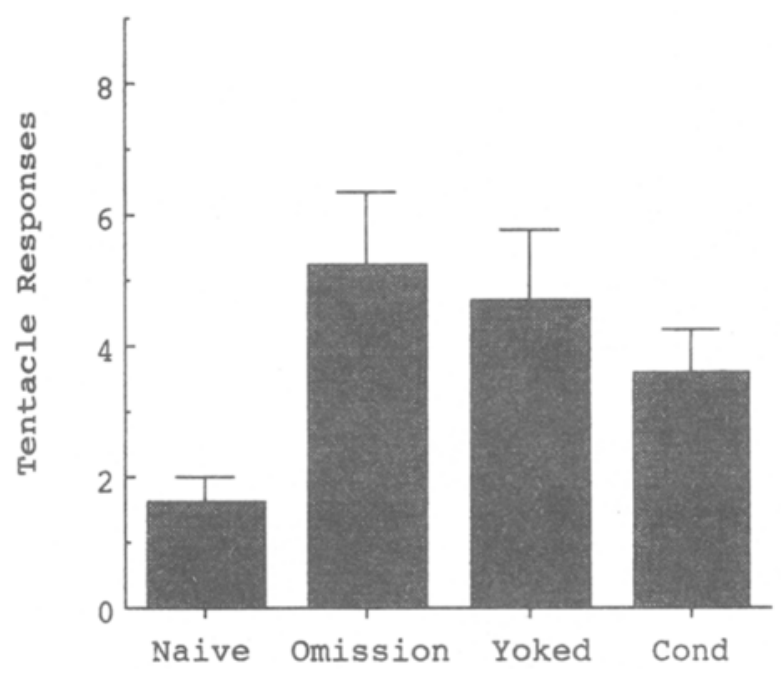

Figure 3. Experiment 3: Mean (+ standard error) number of tentacle lowering responses made by each group: Group Naive received no training; Group Omission received an omission training procedure; Group Yoked received the same stimulus presentations as did Group Omission; Group Cond received the standard conditioning procedure. 
from all five replications were pooled. An ANOVA was carried out, revealing a significant effect of group $[F(3,97)$ $=5.19, p<.005]$. Duncan's post hoc tests revealed significant differences between Group Naive and each of the other groups $(p<.05)$. No other group differences reached significance.

It is clear from these results that the omission schedule did not impair conditioning. On the basis of these results, the instrumental account of food-attraction conditioning can be rejected: The behavioral change is a result of the classical relationship. Since groups Omission and Yoked did not differ, it can also be concluded that the snails (in Group Omission) did not detect the punishing instrumental relationship imposed by the omission schedule. Furthermore, since Groups Cond and Yoked did not differ, it can be concluded that the omission schedule did not result in enhanced classical conditioning, owing to factors such as increased duration of training session, or number of stimulus onsets.

\section{GENERAL DISCUSSION}

Omission procedures have not been used with any of the other gastropod molluscs used to study associative learning. The demonstration of sensory preconditioning in Limax shows that odor-odor learning in that particular case must be classical (Suzuki, Sekiguchi, Yamada, \& Mizukami, 1994); it remains possible, however, that some of the other examples of associative learning, referred to as cases of classical conditioning, might in fact be examples of instrumental conditioning.

The present experiments support the proposal that food-attraction conditioning is a case of appetitive, Pavlovian, classical conditioning. More explicitly, a CS (the odor) comes to be associated with some aspect of the UCS (oral stimulation), which elicits a UCR (lowering the tentacles). Following conditioning, the CS comes to elicit a CR (tentacle lowering). This conclusion has the advantage of presenting food-attraction conditioning as a model for a type of learning found throughout the animal kingdom. Consequently, work with Helix may generate findings of general applicability. In addition, the extensive literature on classical conditioning in other animals, particularly the behavioral literature, should act as a useful guide for investigations with Helix.

It should be noted that although the classical interpretation offered here may not seem surprising, it has been suggested that "food-attraction conditioning is a learning phenomenon which does not conform to the established framework of classical and instrumental conditioning, most often employed to explain invertebrate learning" (Teyke, 1995a, p. 412). The experiments reported here clearly show that food-attraction condition- ing can be described within a classical conditioning framework, and that to do so is helpful.

Finally, it is interesting to ask why the snail lowers its tentacles. It has been suggested that tentacular lowering might be used during food finding behavior (Peschel et al., 1996), although no specific function has been proposed. Despite its plausibility, there is no direct evidence to support this claim. An alternative account emerges from the Pavlovian proposal put forward in the present paper. The snail lowers its tentacles to the CS because the CS has been paired with the UCS. Consequently, what is required is an account of why tentacle lowering occurs during feeding (the UCS), and that remains unclear.

\section{REFERENCES}

Carew, T. J., \& Sahley, C L. (1986). Invertebrate learning and memory. From behavior to molecules. Annual Review of Neuroscience, 9 , 435-487

Chase, R., \& Croll, R. P. (1981). Tentacular function in snall olfactory orientation. Journal of Comparative Physiology A, 143, 357-362.

Croll, R. P., \& Chase, R. (1980). Plasticity of olfactory orientation to foods in the snail Achatina fulica Journal of Comparative Physiology $A, 136,167-177$.

Desbuquois, C., \& Dagl'zan, J (1995). The influence of ingestive conditioning on food choices in the land snail Helix aspersa Muller (Gastropoda, Pulmonata, Stylommatophora). Journal of Molluscan Studies, 61, 353-360

Krasne, F. B., \& Glanzman, D. L. (1995). What we can learn from invertebrate learning. Annual Review of Psychology, 46, 585-624.

Mackintosh, N. J. (1983). Conditioning and associative learning. $\mathrm{Ox}-$ ford. Oxford University Press, Clarendon Press.

Mpitsos, G. J., \& Lukowiak, K. (1985). Learning in gastropod molluscs. In A. O. D. Willows (Ed), Neurobiology and behavior Part 1 (1st ed., Vol. 8, pp. 95-267). New York: Academıc Press.

Peschel, M., Straub, V., \& Teyke, T. (1996). Consequences of foodattraction conditioning in Helix--a behavioral and electrophysiological study. Journal of Comparative Physiology A, 178, 317-327.

Sahley, C. L., Martin, K. A., \& Gelperin, A. (1990). Analysis of associative learnıng in the terrestrial mollusc Limax maximus. II Appetitive learnıng. Journal of Comparative Physiology A, 167, 339345 .

SHEFFIEL, D, F. (1965). Relation between classical conditioning and instrumental conditioning. In W F. Prokasy (Ed.), Classical conditioning A symposium (pp. 302-322). New York Appleton-CenturyCrofts.

Suzuki, H., Sekiguchi, T., Yamada, A., \& Mizlkami, A. (1994). Sensory preconditionıng in the terrestrial mollusk, Limax flavus Zoological Science, 11, 121-125.

TEYKE, T. (1995a). Food attraction conditioning in the snail, Helix pomatia. Journal of Comparative Physiology A, 177, 409-414

TFYKE, T. (1995b). Stımulation to the oral cavity paired with olfactory stimulation promotes "food-attraction conditioning" in Helix. In N. Elsner \& R. Menzel (Eds.), Learning and memory Proceedings of the 23rd Göttingen Neurobiology Conference (p. 13). Stuttgart: Thieme.

TEYKE, T. (1996). Nitric oxide, but not serotonin, is involved in acquisition of food-attraction conditioning in the snail Helix pomatia Neuroscience Letters, 206, 29.

(Manuscript received October 2, 1996; revision accepted for publication May 30, 1997) 